\title{
(6) OPEN ACCESS \\ The practice of palliative care from the perspective of patients and carers
}

\author{
Cathy Sampson, ${ }^{1}$ Ilora Finlay, ${ }^{2}$ Anthony Byrne, ${ }^{1}$ Veronica Snow, ${ }^{3}$ \\ Annmarie Nelson ${ }^{1}$
}

${ }^{1}$ Wales Cancer Trials Unit, Marie Curie Palliative Care Research Centre, School of Medicine, Cardiff University, Cardiff, UK ${ }^{2}$ Department of Palliative Medicine, Velindre Cancer Care Centre, Cardiff, UK

${ }^{3}$ Powys Health Board and South West Wales Cancer Network, Bro Ddyfi Community Hospital, Machynlleth, Powys, UK

\section{Correspondence to} Dr Cathy Sampson, Wales Cancer Trials Unit, Marie Curie Palliative Care Research Centre, School of Medicine, Cardiff University, Cardiff CF5 2LQ, UK; sampsonc2@cf.ac.uk

Received 8 July 2013 Revised 12 November 2013 Accepted 9 December 2013 Published Online First 16 January 2014

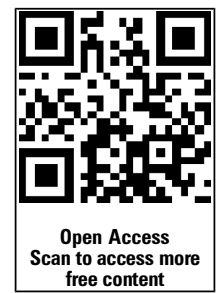

CrossMark

To cite: Sampson C, Finlay I,
Byrne A, et al. BMJ
Supportive \& Palliative Care
2014:4:291-298.

\section{ABSTRACT}

Objectives The meaning that patients and carers attribute to their experience of palliative care is fundamental to the provision, practice and evaluation of optimal care. This analysis aims to establish contemporary key practices and priorities from the perspective of patients and carers.

Methods Thematic analysis was applied to 594 anonymised free text responses from patients and carers documenting their experiences of palliative care.

Results The emotional experience of care is the most significant aspect documented by patients and carers. It refers to the process of care in key domains of respect, renewal, refuge and restorative care. Patients and carers described care as either enabling or directly provided. The emotional experience of care was not confined to psychosocial need and constituted a core practice drawing on professional expertise and interpersonal skills, some of which may be taken for granted by staff themselves.

Conclusions The emotional experience of care is examined as a practice rather than a topic, acknowledging that patients and carers documented the performance of care and the resulting impact in a variety of situations. The emotional experience of care comprises key aspects of contextual care facilitating autonomy and connectedness. It is embedded in relationships mediated by communication and tenor of care. The perspective of patients and carers places the emotional experience of palliative care centrally. This has implications for future service evaluation and the incorporation of this skill-based outcome alongside more traditional outcome measures such as the amelioration of physical symptoms.

\section{INTRODUCTION}

The application of appropriate outcome measures is dependent on understanding the needs of service users. ${ }^{1}{ }^{2}$ The essential contribution of patient and carer perspectives to establishing needs and measuring service provision is recognised $^{3}$ as is the need for clear definitions of service goals, better measures of carer assessment and understanding of carers' unmet needs. $^{4}$

However, natural tensions arise as service providers and commissioners demonstrate awareness of the need to audit the service, but focus on physical or transactional aspects rather than incorporating relational care meeting psychosocial need. ${ }^{56}$ This underestimates the influence that contextual care has on medical outcomes, an area which remains underresearched in terms of understanding and accurate measurement. ${ }^{7}$ Contextual care is comparable with the original philosophy of holistic care in the focus on the patient as part of a wider social network and with psychosocial as well as physical needs. ${ }^{8}$ A significant factor in contextual care remains the interaction of the patient-professional relationship. ${ }^{9}$ The performance of emotional labour, whereby healthcare professionals actively manage relationships with patients, is informally recognised as a key skill facilitating the patient journey. ${ }^{10}$ Through emotional labour, the healthcare professional manages emotion in order to enable the patients to feel reassured and able to express their own feelings and concerns. This professional work contributes fundamentally to the patient experience of care but is not necessarily recognised within the formal assessment of palliative care outcomes.

Although models of practice, instruments and interventions based on concepts such as dignity preservation have been implemented, ${ }^{11}$ the challenge of incorporating the perspectives of health 


\section{Free text box option}

Add your review of the care you received

Please write below what was good and what could be improved

Figure 1 Free text box.

professionals, health providers and service users into an evolving definition of palliative care is ongoing. ${ }^{12}$

A regional palliative care planning group, encompassing all aspects and settings of palliative care, commissioned a service evaluation questionnaire using a combination of closed questions and a free text option in order to base provision of excellent palliative and end-of-life care on understanding the perspectives of patients and their families. ${ }^{13}$

\section{METHODS}

The data set consisted of 594 completed free text responses from the data corpus of 696 questionnaires comprising nine set questions on a Likert scale and a free text box inviting comments on any aspect of palliative care received (figure 1).

In all, 594 completed free text responses from 696 questionnaires were analysed thematically by a qualitative researcher (CS) who was not involved in the palliative care service, in commissioning or implementing the service evaluation. Cross-coding was carried out to ensure methodological rigour (AN) and COREQ guidelines for qualitative research were followed. Two-thirds of responses were from patients and a third from family members who described caring roles and are referred to as carers.

Thematic analysis was interpretive and inductive, reflecting the open ended structure of the free text box. Data were managed using NVivo computer software. ${ }^{14}$ Each data item was anonymised and coded using data extracts as tree nodes and following six key stages: becoming familiar with the data, generating initial codes, searching for themes, reviewing themes, defining and naming themes and reporting the themes (figures 2 and 3). ${ }^{15}$

Interpretive analysis examined the content and the structure of the responses, as the majority of participants had structured the free text response into an outline of change that had occurred as a consequence of palliative care and how this change was accomplished. This resulted in one higher level theme relating to the overall process of care delivery and four subthemes outlining key areas in which patients and carers prioritised palliative care intervention. The local R\&D office was consulted to confirm the validity and ethics of the approach taken. ${ }^{16}$

\section{RESULTS}

\section{The emotional experience of care}

Thematic analysis focused on the meaning participants associated with their palliative care experience. Patients and carers constructed free text responses documenting the consequences of palliative care. Coding focused on a key emergent theme occurring across all aspects and settings of care and

\section{Stage 2 coding from transcript}
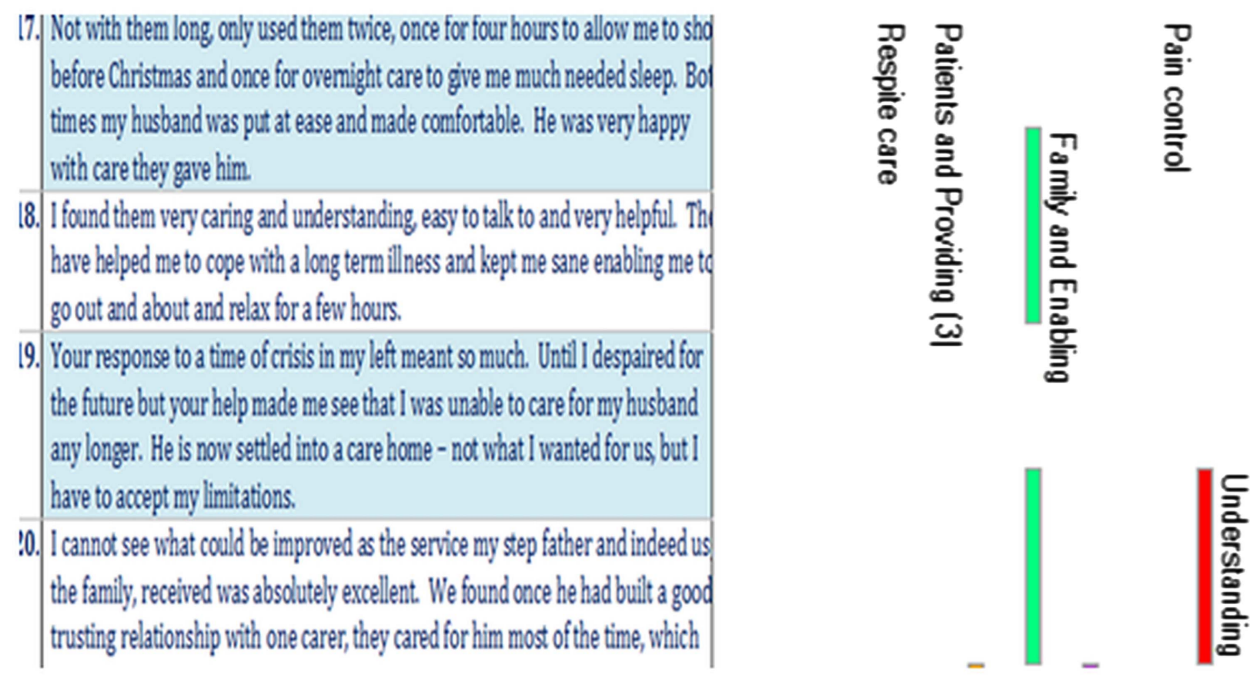

Figure 2 Stage 2 generating initial codes. 


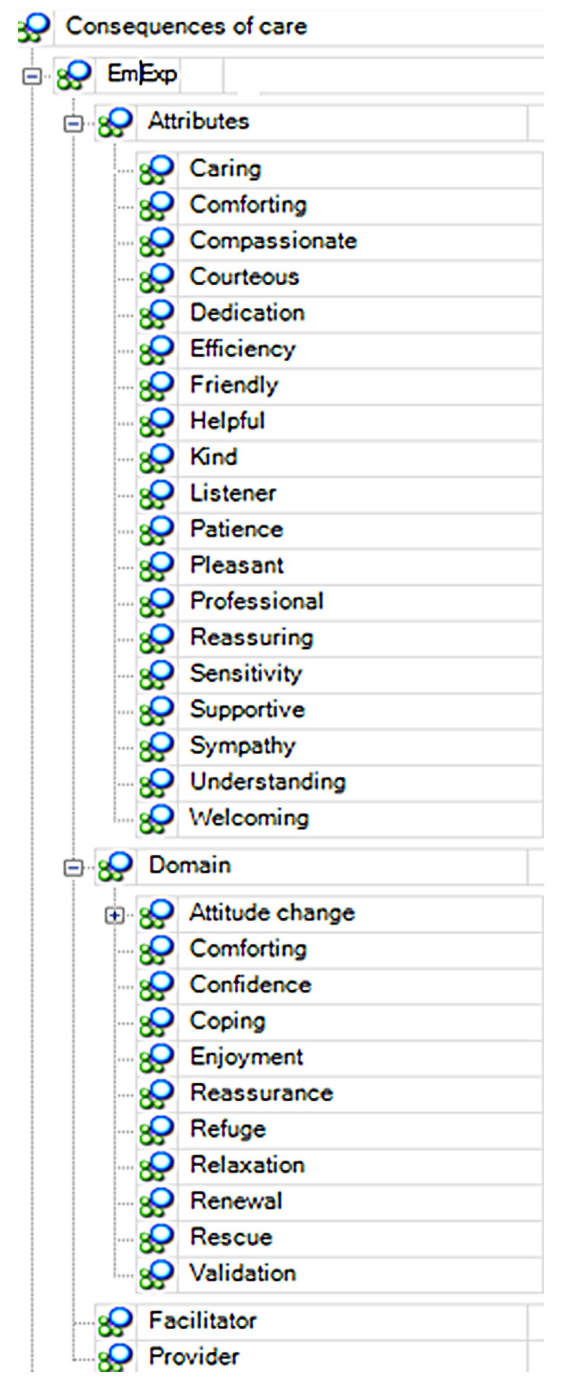

Figure 3 Reviewing themes.

characterising the palliative care experience. This emotional experience of care was coded to include any reference to a change in attitude, affect or ability to cope. These ranged from major shifts in attitude from feelings of despair to feelings of renewal, and more subtle shifts where feelings of security, acceptance or reassurance were expressed. There were four subthemes associated with the emotional experience of care: Respect, Renewal, Refuge and Restorative care (figure 4 ).

\section{Respect}

Emotional labour in healthcare is distinguished by the therapeutic relationship, based on interpersonal skills, professional expertise and multidisciplinary cooperation. ${ }^{17} 18$ References to the atmosphere of the hospice or the tenor of care within the home made the underlying palliative care philosophy visible.

I have been an in-patient on three separate occasions and as someone with terminal cancer I often feel vulnerable as my health slowly deteriorates. [hospice] is the only place that I feel truly safe, and supported by the dedicated doctors and staff. I know that I can trust them to help me feel better.

\section{Hospice inpatient}

Patient and carer responses deconstructed emotional labour into situations and practices illustrating how it is accomplished and the skills it draws upon. Specific skills relating to emotional support attested to the importance of a responsive, empathic presence, where the changing needs of patients, carers and family members, whether physical or psychological, were accepted by staff.

[palliative care nurse] has been the strength and support that we have needed since diagnosis and living each day with cancer. She is always on the end of the phone and no question seems silly to her and she helps us to face the future and realise that all the feelings we have are normal.

Patient: Hospital palliative care outreach service

Patients documented the importance of being allowed to express their feelings or the presence of a palliative care professional as they accomplished the active work of coming to terms with diagnosis and prognosis. Carers valued recognition of their role and being listened to, particularly in relation to fulfilling the wishes of their loved ones. Consequences of respectful care were often practical, such as providing respite care, but rooted in a cooperative, dynamic process with palliative care professionals.

Patients prioritised being treated as a person rather than seen solely in terms of their illness. The complexity of being accepted as an individual and also incorporated into the companionship of others draws upon professional and interpersonal skills.

The staff create a wonderful atmosphere. They are caring and understanding without being too overbearing. Everyone is treated and respected as an individual and yet you are made to feel like one of a large family.

\section{Hospice inpatient}

The mediation of these skills resulted in palliative care that is patient focused and responsive rather than prescriptive and generalised. References to the importance of a good death were coded solely from the responses of carers and family members. Palliative care provided practical but also emotional help in explaining to the patient and their family what the last stages of an illness involved. A significant aspect was the importance to carers of fulfilling the patient's wishes. There was explicit reference of the patient's wish to die at home.

The care that my father received during the last few weeks from the hospice at home team, district nurses and Macmillan nurse was first class and enabled him to die peacefully at home which is what he wanted. 


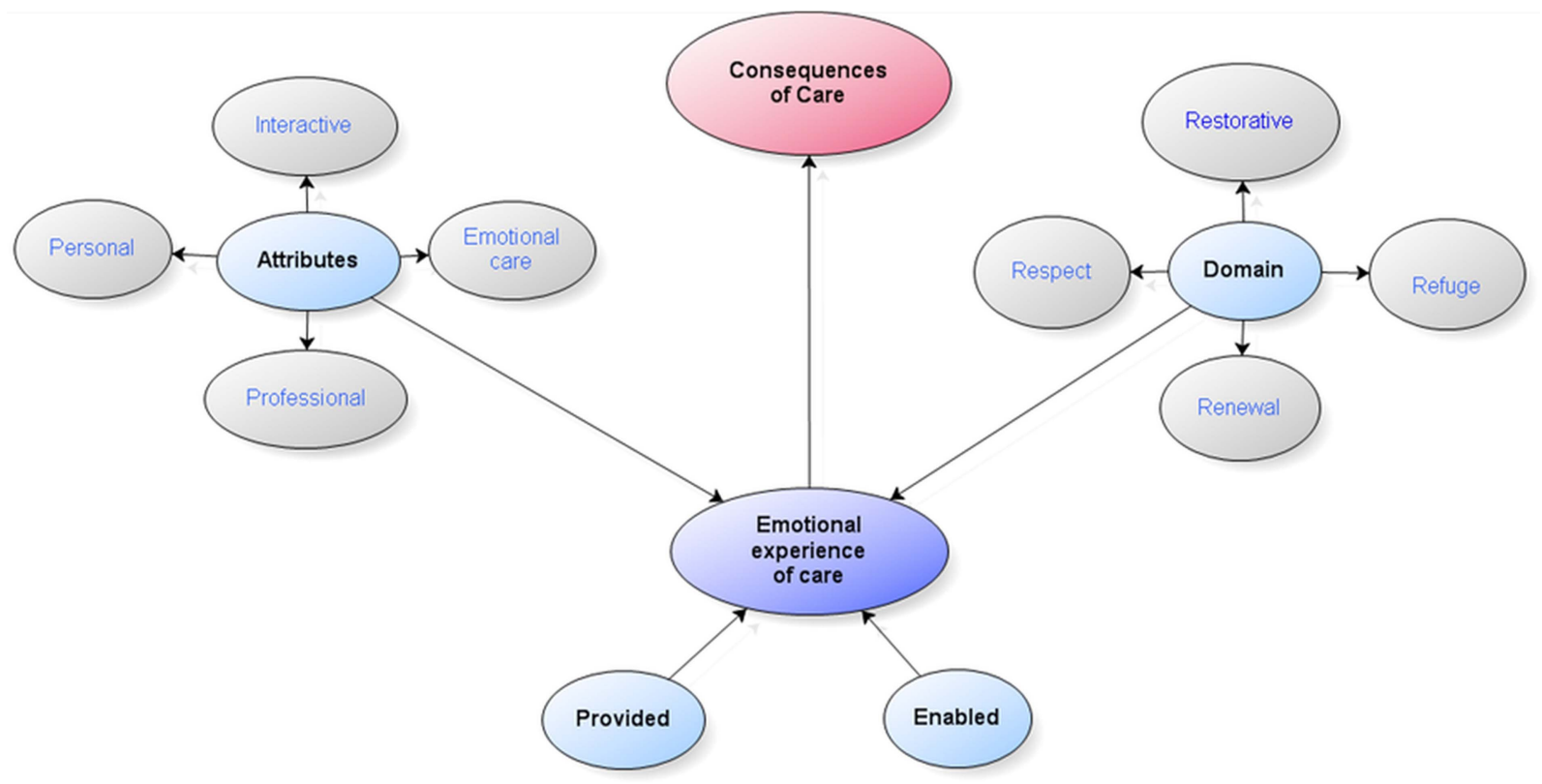

Figure 4 Stage 5 defining and naming themes.

Carer: Community palliative care service

However, the priorities around a good death were communication and the patient's comfort, regardless of where death occurred.

My husband was in the hospice for two weeks before he passed away. The care he received was wonderful. The staff were so caring and compassionate. The aftercare I received was so helpful. It helped me through a very painful time.

Carer

\section{Renewal}

Renewal incorporated changes of attitude, increased confidence or renewed agency. Patients specifically described coming to terms with diagnosis and prognosis.

This [palliative care] has helped me to be more positive and has helped me to accept things and my problems.

Patient: Day hospice

Attitude change in some cases related to the perception of palliative care itself, either by patients or their families.

I would like to say that a lot of people diagnosed with cancer think that 'Hospice' means death. My family thought it, but when I went to my drop in clinic I was proved wrong. They were my life-line with emotional support that my family couldn't cope with.

Patient: Hospice out-patient

Understanding was associated with peer support and with the specialist knowledge of the palliative care service.

Your response to a time of crisis in my life meant so much. Until then I despaired for the future but your help made me see that I was unable to care for my husband any longer. He is now settled into a care home-not what I wanted for us, but I have to accept my limitations.

Carer: Community palliative care service

Patients and carers documented having confidence in the palliative care service, but more significantly described changes to confidence brought about by the intervention of palliative care.

I was glad of the support at [hospice] and they worked as a team to improve my confidence and lighten my anxiety. With their help, I recovered my mental, physical and emotional health.

\section{Hospice inpatient}

Aspects of care contributing to the ability to cope varied from practical help and specialist knowledge to being listened to. Multidisciplinary communication and cooperation across agencies resulted in patients and family members being enabled to approach their situation with renewed confidence.

[palliative care team] efficiently dealt with hospital delays in discharging [the patient] from hospital so we could care for him at home in the last days of his life. They then dealt with all aspects of monitoring his care and co-ordinating the necessary agencies as well as supplying some of the light care and respite care for me. All the people who came to help were efficient, friendly and supportive. It was to [palliative care team] I turned in moments of panic and to understand the changes before death.

Carer: Community palliative care 
An important aspect was the recognition by palliative care staff that terminal illness presents a crisis for the whole family. ${ }^{19}$ Being able to cope was constructed as a contrast between normality and exceptional circumstances, where the contribution of palliative care made it possible to negotiate everyday life.

I found them [palliative care staff] very caring and understanding, easy to talk to and very helpful. They have helped me to cope with a long term illness and kept me sane enabling me to go out and about and relax for a few hours.

Patient: Community based palliative care service

The implication of recognising the enabling aspect of palliative care is that good care may facilitate change in areas of life not necessarily visible or directly apparent to staff.

\section{Refuge}

Palliative and hospice care was repeatedly described as a place of safety, alleviating loneliness and providing a space to express fears that could not be expressed elsewhere.

I was admitted as an in-patient with breathing problems and an inclination towards panic attacks. Immediately upon entering the hospice I calmed down, was able to lay my baggage down. Hospice inpatient

Refuge was also constructed as a psychological aspect of care where it was safe to express both positive and negative emotions.

My problems were addressed and I felt like an individual again. My problems were difficult to treat and my inability to express myself must have been frustrating but I was shown patience and respect and was made to feel safe and cared for until I was ready to move forward again.

Patient: Specialist cancer hospital inpatient

Patients and carers valued flexible palliative care that impacted on the whole family.

My husband is being visited regularly by [palliative care nurse] and he has been a very great comfort and has also provided positive help to us... We know that we can contact him at any time and he will be there for us.

Carer: Community palliative care

Respondents distinguished the palliative care service through consistent care delivery that included volunteers as well as professionals.

I have received the most amazing care from both nurses and volunteers. The unit is run smoothly and I look forward to my [weekly visit] as I know that any problems I have, medically or emotionally, will be addressed and I will receive all the care I need promptly and efficiently. They make a difficult prognosis so much easier to bear.

Patient: Day hospice

Good care was hallmarked by expertise and responsiveness in addition to characteristics such as warmth and sensitivity.

This is a wonderful service, so caring, so efficient, from the top nurse to the volunteers.

\section{Patient: Hospice out-patient}

Refuge, whether located in the hospice or embodied in the palliative care skills of the professional in the home, emphasised the importance of managing transitions between illness stages and helping patients and carers to negotiate uncertainty.

\section{Restorative}

Restorative care relates to therapeutic aspects of care leading to enjoyment or relaxation and directs attention to care of the body. Enjoyment of alternative therapies shifted focus to the context of the body as normal rather than diseased. A fundamental aspect of illness is intimate care of the body. This has been the focus of debate about the status of bodily tasks within healthcare, and the relationship for patients between social well-being, emotional health and limited agency due to illness. ${ }^{17} 20$ Patients described care and respect for the body through use of alternative therapies.

The kindness and professionalism shown to me by staff is exemplary. The complimentary therapy I receive is wonderful, a peaceful haven of normality and I'm sure that without it I would find it far more difficult to cope.

Patient: Day hospice

In addition to bodily deterioration and a terminal diagnosis, patients may experience a social death. ${ }^{21}$ The contribution of good palliative care to being acknowledged as an individual was highlighted by respondents, many of whom expressed enjoyment and satisfaction with the provision of alternative therapies.

The staff and volunteers at [hospice] have without exception been wonderful. So much help and comfort - hands on therapies, explanations of treatments and drugs I'm having. Fellowship, laughter, relaxation, problem solving. You name it, they have done it...

Patient: Hospice out-patient

Acceptance of both the ill body and the associated loss of personhood were present in alternative therapy, where the body was the site of respect rather than of pathology, and where shared experiences validated rather than negated personhood. 


\section{Concerns with palliative care}

Concerns constituted a minor aspect of the free text coding but analysis enabled a deeper understanding of how patients and carers communicate their concerns. Questionnaire scores alone did not provide insight into the nature of concerns but qualitative analysis highlighted that participants structured their responses in two ways, each of which impacted significantly on questionnaire scoring.

Where individual care was good but the context of care was poor, with participants expressing concern about funding, facilities or provision of resources, questionnaire scores reflected satisfaction. This acknowledged good palliative care but highlighted resource concerns, thereby providing support of the service and indicating that provision of better facilities, more staff and extension of service hours were priorities.

Excellent team done by a dedicated team. Treatment and counselling second to none. Could do with their own clinic, more money and resources.

\section{Patient: Hospice community service}

Where there was a concern with specific care this was reflected in lower questionnaire scores and related to issues around communication and consideration of individual need.

The care was very good in the beginning but I did feel as though as soon as my treatment had finished I had been dropped. Although my palliative care nurse said I was able to telephone if there were any problems I felt as though I was bumbling along without any help or visits-there were still many issues I wanted help with.

Patient: Community palliative care service

Patients and carers clearly distinguished between their individual care and the wider context within which palliative care functions.

\section{DISCUSSION}

Psychosocial dimensions of palliative care coexist alongside provision of pain and symptom control and are implicitly recognised by staff and patients. ${ }^{22}$ However, the challenges of collecting routine data from a population with a terminal prognosis, the difficulties of adequately defining aspects of psychosocial care and the necessity of concentrating on measurable aspects of care to justify economic considerations have led to tension between meeting more easily defined practical outcomes and evaluating contextual outcomes such as tenor of care. ${ }^{23} 24$

Palliative and end-of-life care requires detailed recording of communication processes and service users' feedback in addition to expert consensus on demonstrable indicators that improve outcomes. ${ }^{25}$ The limitations of the scientific method in measuring humane aspects of care such as dignity and attentiveness are recognised, as is the need for these factors to be fully recognised as impacting directly on the quality of care. ${ }^{26}$

Free text analysis highlights the fundamental importance of the emotional experience of care to patients and carers. It describes the specific skills and practices that constitute good palliative care, implying a mobile set of skills united by a common philosophy and embodied in the palliative healthcare professional. Good care is distinguished by characteristics such as expertise, enablement and efficiency within the context of respectfulness.

Understanding the significance of the emotional labour involved in caring is relevant to the practice of palliative care where it occurs in multiple settings across the community and not solely in institutions such as hospices or hospitals. The contribution of volunteers was significant, highlighting the importance of supporting their role. ${ }^{27}$

The practice of emotional labour is influenced by changing expectations both organisationally and within wider society. ${ }^{28} 29$ The changing consumer orientated culture of healthcare has led to emotion work changing from an intrinsic contract between healthcare professional and patient to caring as a commodity. ${ }^{30} 31$ However, although structural changes within the caring professions may impact on the satisfaction and ability of professionals to carry out their duties, the core expectation of the therapeutic relationship remains a source of satisfaction. $^{32}$ The challenge remains of acknowledging skills that have been devalued, yet which healthcare professionals see as central to their role. ${ }^{10}$ Free text analysis highlights that the emotional experience of care is highly valued by patients and carers and the attendant emotional labour is recognised and described revealing palliative care as enabling as well as provided. This is significant as lack of control and agency are key concerns for patients, in addition to the need for information, and practical and psychosocial support. ${ }^{33}$ Feelings of helplessness or lack of autonomy are also associated with greater difficulty for carers coping in stressful situations and following bereavement. ${ }^{34}$

A distinction has been made between professional competencies, which can be learnt, and professional judgements, which are based in practice and experience ${ }^{35}$ and arise from the dynamic relationship between patients and professionals. ${ }^{36}$ Underevaluated aspects of palliative care include the professional and interpersonal skill of health professionals who have an intuitive understanding of the care they provide but may not recognise or define these aspects in a measurable way. ${ }^{37}$ Free text analysis contributes to an understanding of the skills that are valued by patients and carers and offers insight into the domains in which these aspects of palliative care make a significant impact.

\section{CONCLUSIONS}

Palliative care was founded on a holistic philosophy encompassing the physical, psychosocial and spiritual 
needs of patients with a terminal prognosis and their family. ${ }^{8}$ Contemporary palliative care acknowledges the contextual nature of care but there is tension between evaluating formal aspects of care delivery such as pain relief and service processes while giving equal recognition to aspects such as tenor of care.

When service users were invited to complete the service evaluation free text survey box to comment on any aspect of their care, the qualitative analysis indicated overall satisfaction with the palliative care service. Service users structured their responses around their experiences of how care was delivered. This process of care delivery focused on the emotional experience of care and incorporated aspects associated with tenor of care such as agency, dignity and acceptance. The free text analysis highlights the importance of the emotional experience of care to patients and carers, providing insight into specific examples of where and how this care occurs. Specific expectations from the perspective of patients and carers are of professionalism, expertise and facilitation. The emotional experience of care encompassed practical and psychological outcomes but was characterised by the expression of renewed agency where a shift in attitude had occurred.

Free text analysis indicates that the impact of palliative care may not be fully evident to health professionals or providers, and that aspects of palliative care practice that may be either taken for granted or not fully recognised are significant for patients and carers.

The importance of contextual issues for patients and carers and the significance of the emotional experience of care indicate that they are essential components of good palliative care practice that should be included in future evaluation of the palliative care service.

Funding This work was supported by Marie Curie Cancer Care core grant funding to the Marie Curie Palliative Care Research Centre, Cardiff University. Dr. Annmarie Nelson and Dr. Anthiny Byrne's posts are supported by Marie Curie Cancer Care core grant funding.

Contributors IF conception and design of the service evaluation in Wales and acquisition of core data; CS and AN analytic input; CS article drafting; all authors article revision and approval of the final version.

\section{Competing interests None.}

Ethics approval Dr Corinne Scott consulted local ethics board and formal ethical approval not required.

Provenance and peer review Not commissioned; externally peer reviewed.

Open Access This is an Open Access article distributed in accordance with the Creative Commons Attribution Non Commercial (CC BY-NC 3.0) license, which permits others to distribute, remix, adapt, build upon this work noncommercially, and license their derivative works on different terms, provided the original work is properly cited and the use is non-commercial. See: http://creativecommons.org/licenses/by$\mathrm{nc} / 3.0 /$

\section{REFERENCES}

1 Granda-Cameron C, Viola S, Lynch M, et al. Measuring patient-oriented outcomes in palliative care: functionality and quality of life. Int J Palliative Nursing 2010;16:445-50.

2 Seow H, Snyder C, Shugarman L, et al. Developing quality indicators for cancer end-of-life care: proceedings from a national symposium. Cancer 2009;115:3820-9.

3 Grande G, Stajduhar K, Aoun S, et al. Supporting lay carers in end of life care: current gaps and future priorities. Palliat Med 2009;23:339-44.

4 Harding R, Higginson I. What is the best way to help caregivers in cancer and palliative care? A systematic literature review of interventions and their effectiveness. Palliat Med 2003;17:63-74.

5 Hudson P, Remedios C, Thomas K. A systematic review of psychosocial interventions for family carers of palliative care patients. BMC Palliat Care 2010;9:17.

6 Lorenz K, Lynn J, Dy S, et al. Evidence for improving palliative care at the end of life: a systematic review. Ann Intern Med 2008;148:147-59.

7 van Driel M, De Sutter A, Thierry C, et al. Quality of care: the need for medical, contextual and policy evidence in primary care. J Eval Clin Pract 2005;11:417-29.

8 Saunders C. Social work \& palliative care-the early history. Br J Soc Work 2001;31:791-9.

9 Tracy C, Dantas G, Moineddin R, et al. The nexus of evidence, context, and patient preferences in primary care: postal survey of Canadian family physicians. BMC Fam Pract 2003;4:13.

10 Mann S. A health-care model of emotional labour: an evaluation of the literature and development of a model. J Health Organ Manag 2005;19:304-17.

11 Monod S, Brennan M, Rochat E, et al. Instruments measuring spirituality in clinical research: a systematic review. J Gen Intern Med 2011;26:1345-57.

12 Payne $S$. The cancer experiences collaborative: better research by better researchers. Palliat Med 2011;25:739-40.

13 Finlay I. Developing a template to plan palliative care services: the welsh perspective. J Pain Symptom Manage 2009;38:81-6.

14 Lewins A, Silver C. Using software in qualitative research. LA: Sage, 2007.

15 Braun V, Clarke V. Using thematic analysis in psychology. Qual Res Psychol 2008;3:77-101.

16 NHS Research \& Development Forum. Defining Research. 2010. http://www.nres.npsa.nhs.uk/news-and-publications (accessed 17 Mar 2012).

17 Theodosius C. Emotional labour in health care: the unmanaged heart of nursing. Oxon: Routledge, 2008.

18 Hochschild A. The managed heart: the commercialization of human feeling. Berkeley: University of California Press, 1983.

19 Mehta A, Cohen S, Chan L. Palliative care: a need for a family systems approach. Palliat Support Care 2009;7:235-43.

20 Shilling C. The body and social theory. London: Sage, 2005.

21 Lawton J. The dying process: patients' experiences of palliative care. London: Routledge, 2000.

22 Chochinov $\mathrm{H}$. Dying, dignity, and new horizons in palliative end-of-life care. CA Cancer J Clin 2006;56:84-103.

23 Payne S, Sheldon F, Jarrett N, et al. Differences in understanding of specialist palliative care amongst service providers and commissioners in London. Palliat Med 2002;16:395-402. 
24 Jocham H, Dassen T, Widdershoven G, et al. Evaluating palliative care-a review of the literature. Palliat Care Res Treat 2009;3:5-12.

25 Grande G, Preston N. The need for new perspectives on evaluation of palliative care. Palliat Med 2011;25:737-8.

26 Bregni M. Quality of life and meaning of life: measuring the unmeasurable. J Med Pers 2010;8:60-4.

27 The King's Fund. Delivering better care at end of life. London: The King's Fund, 2009.

28 Stets J, Turner J, eds. Handbook of the sociology of emotions. New York: Springer, 1996.

29 Wharton A. The sociology of emotional labor. Annu Rev Sociol 2009;35:147-65.

30 Bolton S. Changing faces: nurses as emotional jugglers. Sociol Health Illn 2001;23:85-100.

31 Bone D. Dilemmas of emotion work in nursing under market-driven health care. Int J Public Sector Manag 2002;15:140-50.
32 Hunyh T, Alderson M, Thompson M. Emotional labour of nursing care: an evolutionary concept analysis. J Adv Nurs 2009;64:195-208.

33 Seymour J, Ingleton C, Payne S, et al. Specialist palliative care: patients' experiences. J Adv Nurs 2003;44:24-33.

34 Milberg A, Strang P. Protection against perceptions of powerlessness and helplessness during palliative care: the family members' perspective. Palliat Support Care 2011;9:251-62.

35 Schon D. Educating the reflective practitioner: towards a new design for teaching and learning in the professions. San Francisco: Jossey-Bass, 1987.

36 Hillier R, Wee B. From cradle to grave: palliative medicine education in the UK. J R Soc Med 2001;94:468-47.

37 NICE (National Institute for Clinical Excellence). Guidance on cancer services: improving supportive and palliative care for adults with cancer. London: National Institute for Clinical Excellence, 2004. 